\title{
REMOTELY PILOTED AIRCRAFT SYSTEM AIR VEHICLE WING AIRFOIL SELECTION
}

\author{
Nikolajs Glizde, Margarita Urbaha \\ Riga Technical University, Latvia \\ nikolajs.glizde@edu.rtu.lv, margarita.urbaha@rtu.lv
}

\begin{abstract}
The research is focused on development of Unmanned Aircraft System. For design purposes Systems Engineering Approach is used. This paper describes concise research for Unmanned Aircraft System air vehicle preliminary developments phase. The design is focused on development of micro Unmanned Aircraft System with long range and endurance capabilities. In current paper UAS air vehicle wing airfoil selection process is described. In previous design steps the air vehicle type for Unmanned Aircraft system was selected that is flying wing configuration. The flying wing air vehicles have inherent stability and controllability problems that should be eliminated selecting right airfoil shape. In wing airfoil selection Multidisciplinary Optimization Method is used to get airfoil that will give necessary results to reach design goals. Most frequently used Multidisciplinary Optimization Method are Finite Difference, Implicit Function Theorem, Stepping Search Methods, Response Surface, Monte Carlo, Random Walk and Simulated Annealing, Evolutionary Algorithms and Evolution Strategy, Genetic Algorithms, Decomposition. In current research for airfoil selection Stepping Search Method was used. Obtained results provided clear and uncompromising information for further design steps and complete wing design.
\end{abstract}

Keywords: aircraft, wing design, unmanned, air vehicle, engineering approach, aerodynamics.

\section{Introduction}

This is the conceptual design phase during which the air vehicle is designed with non-precise results. All parameters are determined based on design requirements, calculations, a decision-making process and a selection technique. At this phase the air vehicle wing airfoil type will be determined.

In this design phase the results from previous of calculations are used. The airfoil selection procedure should be followed very carefully because it should be selected for flying wing air vehicle construction. The legacy deficiency for the flying wing type air vehicle is poor stability and control characteristics, that partly can be solved with right airfoil selection. In previous design phase also following three aircraft fundamental parameters were determined: maximum take-off weight (MTOW), wing reference area $\left(S_{r e f}\right)$, and engine power $(P)$ [1-9].

\section{Wing design parameters}

In initial design phase following parameters were determined:

- The air vehicle MTOW - $78.61 \mathrm{~N}$;

- Electric motor power $-0.82 \mathrm{~kW}$;

- The wing reference area $-1.1102 \mathrm{~m}^{2}$.

In this design step the wing will be designed. The wing can be considered as the main aircraft component as the aircraft can nit fly without it if it is not rotary wing/helicopter type. As the wing geometric planform and parameters influence all other air vehicle components, the detailed design phase begins with the wing design. The wing primary function is to produce necessary lift force $(L)$, but besides it has two more parameters - the drag $(D)$ and the nose down pitching moment $(M)$. In design process main task is to maximize lift force and to minimize other two [6-9].

In this design step sophisticate software calculations are not necessary so simple lifting-line theory will be used to evaluate $L, D$ and $M$ parameters with enough accuracy $[1-3 ; 10 ; 11]$.

\section{The wing airfoil section}

In this step the wing airfoil section type will be selected. The wing airfoil type is second most important parameter after wing reference area. The airfoil shape determine optimal pressure distribution between upper and lower surfaces of the wing in such way that the necessary lift force is created with the least aerodynamic loss (drag and pitching moment).

Necessary airfoil will be determined in selection process. The airfoil will be selected from existing data bases after carful parameter determination, comparison and optimisation procedure. 
Generally, are available three airfoil data bases - NACA (previously National Advisory Committee for Aeronautics or currently NASA - National Aeronautics and Space Administration), Eppler and Wortman. For remotely piloted aircraft system air vehicle wing airfoil will be selected from Eppler and Wortman data bases as those airfoils are design for small and very small Reynolds numbers [12-22].

The aircraft flight consists of take-off, clime, cruse, turn, manoeuvre, dissent, approach and landing. Basically, wing airfoil section shape optimal function is in cruise flight as the aircraft most part of its flight time spends in this phase. The lift force $(L)$ during cruise flight is equal to the aircraft weight $(W)$, and, drag force $(D)$ is equal to engine power $(P)$, so the wing should create enough lift force and the drag force should be minimum. Both mentioned parameters are defined by the wing airfoil section shape and for cruising flight following equations are in force:

$$
\begin{gathered}
L=W \Rightarrow \frac{1}{2} \rho V^{2} S C_{L}=m g, \\
D=T \Rightarrow \frac{1}{2} \rho V^{2} S C_{D}=\frac{n \eta_{P} P_{\max }}{v_{C}} .
\end{gathered}
$$

The equation (2) is true for prop-driven engine. The variable $\mathrm{n}$ is taken in range from $0.6-0.9$, that means that during cruise flight only part of engine power is used but not maximum. In this case the value of 0.75 is advisable but more precise value will be determined in further calculations. The engine maximum power is used only during aircraft take-off phase.

During the wing airfoil shape selection process the attention should be payed not only on geometrical shape or pressure distribution on its surface but also airfoil section operational results that will give more information about its compliance to design requirements. There are several graphical charts from which the airfoil performance characteristics can be evaluated. Mainly those are graphical charts that show dimensionless lift, drag and pitching moment factor variations depending on angle of attack. Mentioned factors could be calculated with following equations:

$$
\begin{gathered}
C_{l}=\frac{l}{\frac{1}{2} \rho V^{2}(C \cdot l)}, \\
C_{d}=\frac{d}{\frac{1}{2} \rho V^{2}(C \cdot l)}, \\
C_{m}=\frac{m}{\frac{1}{2} \rho V^{2}(C \cdot l) \cdot C},
\end{gathered}
$$

where $l, d$ and $m$ - two-dimensional wing airfoil section lift force, drag force and pitching moment;

$(\mathrm{C} \times l)$ - taken as wing airfoil section chord multiplied by wingspan $(b=1)$.

To summarize, the wing airfoil section performance and characteristics are evaluated from following graphical charts:

1. Lift factor versus angle of attack.

2. Pitching moment factor against quarter-chord versus angle of attack.

3. Pitching moment factor against quarter-chord versus lifting factor.

4. Drag factor versus lifting factor.

5. Lifting and drag factor relation versus angle of attack.

In following section shortly will be reviewed mentioned graphical charts.

\section{The lift factor $\left(C_{l}\right)$ versus angle of attack $(\alpha)$ graphical chart}

The lifting factor $\left(C_{l}\right)$ versus angle of attack $(\alpha)$ graphical chart show wing airfoil section seven important parameter performance: stall angle $\left(\alpha_{s}\right)$, maximum lift factor $\left(C_{l \max }\right)$, zero angle of attack 
$\left(\alpha_{o}\right)$ and corresponding angle of attack $\left(C_{l o}\right)$, ideal lift factor $\left(C_{l i}\right)$ and corresponding angle of attack $\left(\alpha_{C l i}\right)$ and lifting force curve slope $\left(C_{l \alpha}\right)$.

The pitching moment factor $\left(C_{m}\right)$ against quarter-chord versus angle of attack $(\alpha)$ graphical chart

The pitching moment factor $\left(C_{m}\right)$ versus angle of attack $(\alpha)$ graphical chart curve usually is negative and also in negative $C_{m}$ area for typical range of angle of attack. Negative slope is preferable because it is stabilizing in case if angle of attack is disturbed by gust. Negative $C_{m}$ moment sometimes is called also nose-down pitching moment. That is because it is in negative direction against y-axe and airplane nose will swing down from such moment.

\section{The pitching moment factor $\left(C_{m}\right)$ against quarter-chord versus lift factor $\left(C_{l}\right)$ graphical chart}

The pitching moment factor $\left(C_{m}\right)$ versus lift factor $\left(C_{l}\right)$ graphical chart usually is constant for some lifting factor range. Usually $C_{m}$ is in range from -0.02 to -0.05 .

The reason is that the aircraft should be in equilibrium during cruising flight. Longitudinal pitching moment should be balanced with other aircraft component such as tail. So bigger $C_{m}$ (negative value) then bigger tail is necessary that also means heavier aircraft.

In this case when tailless flying wing air vehicle is designed very careful attention should be payed to airfoil section and its $C_{m}$ value.

\section{The drag factor versus lifting factor $\left(C_{l}\right)$ graphical chart}

The typical drag factor coefficient $\left(C_{d}\right)$ versus lifting factor $\left(C_{l}\right)$ graphical chart is with positive curve. The graphical chart lowest point is minimum drag factor $\left(C_{d \min }\right)$ and corresponding minimum lift factor $\left(C_{l \min }\right)$.

The line which is drawn from axes canter as tangent to curve shows point at which maximum factor $C_{l}-C_{d}$ relation is found or $\left(C_{d} / C_{l}\right)_{\min }=\left(C_{l} / C_{d}\right)_{\max }$. This relation should be as higher as possible. It gives aircraft maximum endurance. General both mentioned parameters with ideal values in one airfoil section cannot be obtained but based on operational and design requirements to one of them more attention is payed.

\section{The lifting and the drag factor relation $\left(C_{l} / C_{d}\right)$ versus angle of attack $(\alpha)$ graphical chart}

The typical lifting and drag factor relation $\left(C_{l} / C_{d}\right)$ versus angle of attack $(\alpha)$ graphical chart is with negative curve. The graphical chart highest point shows maximum $\left(C_{l} / C_{d}\right)_{\max }$ relation value. The angle of attack which corresponds to this maximum $\left(C_{l} / C_{d}\right)_{\max }$ relation value is optimal for loitering flight $\left(\alpha_{l}\right)$.

\section{The wing airfoil selection criteria}

The wing airfoil selection begins with clear definition of flying requirements. In the design process attention should be payed also to other requirements as airworthiness, structure, producibility and cost. Generally, for wing airfoil section selection from design requirement point of view are used following criteria:

1. The wing airfoil section with maximum lift factor $\left(C_{l \max }\right)$.

2. The wing airfoil section with appropriate ideal or design lift factor $\left(C_{l d}\right.$ or $\left.C_{l i}\right)$.

3. The wing airfoil section with smallest minimum drag factor $\left(C_{d \min }\right)$.

4. The wing airfoil section with highest lift-to-drag ratio $\left(\left(C_{l} / C_{d}\right)_{\max }\right)$.

5. The wing airfoil section with highest lift curve slope $\left(C_{l a \max }\right)$.

6. The wing airfoil section with smallest (near to zero; negative or positive) pitching moment factor $\left(C_{m}\right)$.

7. Appropriate stalling quality in curve stalling region (with gradual changes, not sharp).

8. The wing airfoil section should be structurally reinforceable, with enough sickness to emplace reinforcement structure.

9. The wing airfoil section should be producible.

10. Should be considered other design requirements, for example, if the fuel tank is designed to be in the wing, there must be enough space for it. 
11. If more than one wing airfoil section is considered for wing, then two airfoil section integration should be viewed.

Usually it is impossible to find one airfoil section with optimal values for all above mentioned requirements. For example it is possible to find airfoil section with highest $C_{l \max }$ value but it will not be with highest $\left(C_{l} / C_{d}\right)_{\max }$ value. So, the procedure should be followed to find the best airfoil section for specific design with optimal solution [12-22].

\section{The wing airfoil section selection practical procedure}

In the practical wing airfoil section selection will be used data bases of EPPLER and WORTMAN airfoils which provide very low and low Reynolds number airfoils. Alternatively, also will be reviewed NACA, CLARK, GOE, RAE \& RAF, and some Martin Heppler airfoils that are designed for flying wings.

Reviewed EPPLER and WORTMAN data bases consisted totally 323 airfoils and 9 (nine) Martin Heppler airfoils. From this number, 19 (nineteen) airfoils of EPPLER, 2 (two) airfoils of WORTMAN and 7 (seven) airfoils of Martin Heppler were selected for further research. Deeper research showed that for further consideration 6 (six) airfoils are acceptable, that are, one WORTMAN airfoil fx66h80, one Martin Heppler airfoil mh110 and four EPPLER airfoils - e186, e330, ea61009, ea81006 [21].

Following are selection procedure in steps.

\section{Remotely piloted aircraft system air vehicle weight}

As for RPAS air vehicle propulsion electrical motor will be used the weight during cruising flight does not change. The weight was determined already in previous calculations $-W=78.61 \mathrm{~N}$.

The air vehicle cruising lift factor $\left(C_{L C}\right)$

During cruising flight, the air vehicle weight is equal to lift force:

$$
C_{L_{C}}=\frac{2 W}{\rho V_{C}^{2} S}=\frac{2 \cdot 78.61}{1.184 \cdot 20.20^{2} \cdot 1.1102}=0.29312,
$$

where $V_{C}$ - the air vehicle cruising flight speed, $\mathrm{m} \cdot \mathrm{s}^{-1}$;

$\rho$ - the air density at cruising flight altitude, $\mathrm{kg} \cdot \mathrm{m}^{-3}$;

$S$ - the wing reference area, $\mathrm{m}^{2}$.

The air vehicle wing cruising lift factor $\left(C_{L C w}\right)$

Basically, the wing is considered only for lift development but there are also aircraft components that also invest in total lift production (negative or positive), sometimes even until $20 \%$. While other component geometrical shapes are not defined the wing lift factor can be determined from following equation:

$$
C_{L_{C_{W}}}=\frac{C_{L_{C}}}{0.95}=\frac{0.29312}{0.95}=0.30855
$$

This parameter will be specified in further design phase when other components design is known.

The wing airfoil section ideal lift factor $\left(C_{l i}\right)$

The wing is three-dimensional item, but the wing airfoil section is two dimensional. Taking into consideration that wing chord is constant, without sweep, dihedral and span is taken as infinite, then theoretically wing lift factor should be the same as wing airfoil section lift factor. In this design step, when other wing design parameters are unknown, the approximate values should be used. For calculation following approximation equation can be used:

$$
C_{l i}=\frac{C_{L_{C_{W}}}}{0.9}=\frac{0.30855}{0.9}=0.34284
$$

In further design steps this parameter will be recalculated taking into account wing design parameters and airfoil section type. 
The air vehicle maximum lift factor $\left(C_{L \max }\right)$

The air vehicle maximum lift factor is calculated from following equation:

$$
C_{L_{\max }}=\frac{2 W}{\rho_{0} V_{S}^{2} S}=\frac{2 \cdot 78.61}{1.225 \cdot 8.5^{2} \cdot 1.1102}=1.6000466,
$$

where $V_{S}$-air vehicle stall flight speed;

$\rho_{0}-$ the air density at sea level.

The wing maximum lift factor $\left(C_{L \max \_w}\right)$

For the same reason that was described in the air vehicle wing cruising lift factor calculation, that is while other air vehicle component geometrical shape are not defined the wing maximum lift factor can be determined from following approximation equation:

$$
C_{L_{\max -w}}=\frac{C_{L_{\max }}}{0.95}=\frac{1.6000466}{0.95}=1.6843 .
$$

The wing airfoil section gross maximum lift factor $\left(C_{\text {lmax_gross }}\right)$

The wing airfoil section gross maximum lift factor is calculated from following equation:

$$
C_{l \text { max }_{-} \text {ross }}=\frac{C_{L_{\text {max } \omega}}}{0.9}=\frac{1.6843}{0.9}=1.8714,
$$

where the wing airfoil section gross maximum lift factor is the aitfoil section maximum lift factor with high lift device (flap) effect (HLD).

\section{Design/select high lift device (HLD)}

In this step HLD type, geometrical shape and maximum deflection will be determined. High lift device deflection creates following changes in wing airfoil section parameters:

1. Increase of lift factor $\left(C_{l}\right)$;

2. Increase of maximum lift factor $\left(C_{l \max }\right)$;

3. Change in zero-lift angle of attack $\left(\alpha_{0}\right)$;

4. Change in stall angle $\left(\alpha_{s}\right)$;

5. Change in pitching moment factor $\left(C_{m}\right)$;

6. Increase of drag factor $\left(C_{d}\right)$;

7. Increasing of lifting cure slope $\left(C_{l \alpha}\right)$.

Reviewing all possible HLD design possibilities [15; 23] and taking into consideration other design requirements as performance and cost, decision is made to stay with plain flap design that most possibly will be constructed on outboard or outboard-midboard wing parts.

For flap design following parameters are defined:

1. Location from wingspan: located on wing trailing edge, on outboard/midboard wing parts until 70 $\%$ of wingspan, rectangular or trapezoidal shape that will be specified later after wing planform determination.

2. High Lift Device type: the air vehicle is for mini class RPA system, considering manufacturing, maintenance and cost the plain flap type is chosen [15;23].

3. HLD chord $\left(C_{f}\right)$ : flap chord in this design stage is defined $20 \%$ of wing mean chord:

$$
C_{f}=C_{m g c} \cdot 0.2=0.372525 \cdot 0.2=0.074505 \mathrm{~m} \approx 75 \mathrm{~mm} .
$$

4. HLD span $\left(b_{f}\right)$ : flap span in this design stage is defined $70 \%$ of wingspan:

$$
b_{f}=b \cdot 0.7=2.98 \cdot 0.7=2.086 \mathrm{~m} \text {. }
$$

Then the half wing HLD span is $b_{f} / 2=1.043 \mathrm{~m}$

5. HLD maximum deflection $\left(\delta_{\text {fmax }}\right)$ : 


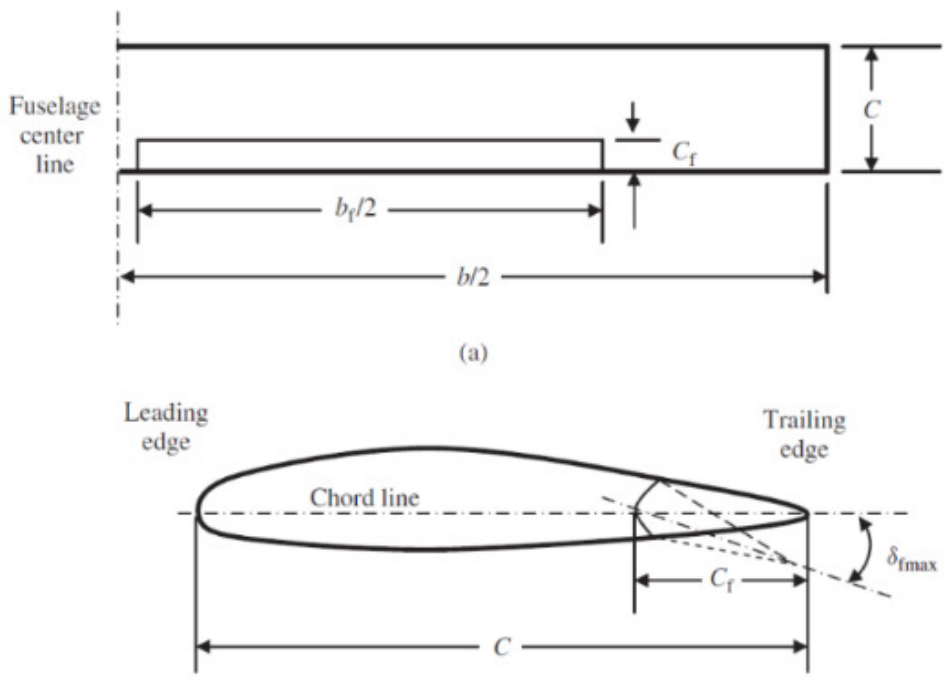

(b)

Fig. 1. Flap $(\boldsymbol{H} L \boldsymbol{D})$ parameters: a - right wing top view; $\mathrm{b}$ - inboard part sideview (flap deflected)

For this calculation phase flap maximum deflection is accepted $20^{\circ}$ up and down deflection.

6. Determine HLD investment in maximum lift factor $\left(\Delta C_{l H L D}\right)$. According to chosen flap type in this design phase flap investment in maximum lift factor is accepted 0.8 [15]. In further calculations, when parameters is specified, this value will be corrected.

The wing airfoil net maximum lift coefficient $\left(C_{\text {lmax }}\right)$ :

$$
C_{l_{\max }}=C_{l_{\text {max }} \text { gross }}-\Delta C_{l_{H L D}}=1.8714-0.8=1.0714 .
$$

Determination of wing airfoil section alternative types

In this step other possible alternative types of wing airfoil sections that deliver desired $C_{l i}$ and $C_{l \max }$ are determined. The selection alternatives are shown in Table 2 with parameter comparison and selection procedure. In the table (Table 2) six wing airfoil section alternatives and their parameters with defined weighed values according to design requirements are shown [23-25].

Table 1

The wing airfoil section type selection

\begin{tabular}{|c|c|c|c|c|c|c|c|c|}
\hline No. & $\begin{array}{c}\text { Design } \\
\text { Objective }\end{array}$ & $\begin{array}{c}\text { Weighed } \\
\text { Value, \% }\end{array}$ & $\mathbf{f x 6 6 h 8 0}$ & $\mathbf{m h 1 1 0}$ & $\mathbf{e 1 8 6}$ & $\mathbf{e 3 3 0}$ & ea61009 & ea81006 \\
\hline 1. & $C_{d \min }$ & 20 & 0.0145 & 0.01284 & 0.01414 & 0.01595 & 0.01295 & 0.00986 \\
\hline 2. & $C_{m 0}$ & 25 & -0.0044 & 0.0099 & -0.0019 & -0.0096 & -0.0052 & -0.0038 \\
\hline 3. & $\alpha_{s}$ & 10 & 9.9 & 11.6 & 10.2 & 10.7 & 8.2 & 8.0 \\
\hline 4. & $\alpha_{0}$ & 10 & -1 & -1.1 & -1.5 & -1.9 & 0.0 & 0.0 \\
\hline 5. & $\left(C_{l} / C_{d}\right)_{\max }$ & 20 & 47.5 & 39.0 & 46.0 & 40.6 & 29.5 & 22.7 \\
\hline 6. & $C_{l \alpha}$ & 5 & 6.0137 & 6.1042 & 6.1132 & 6.1494 & 6.0589 & 5.9233 \\
\hline 7. & Stall Quality & 10 & 4 & 8 & 6 & 6 & 4 & 5 \\
\hline \multicolumn{2}{|c|}{ Total: } & 100 & $\mathbf{6 5 . 5}$ & 64.8 & $\mathbf{7 2 . 5}$ & 64.3 & 55.1 & 55.8 \\
\hline 8. & $C_{d c}$ & 20 & 0.01416 & 0.01425 & 0.01531 & - & - & - \\
\hline 9. & $C_{l a s}$ & - & 1.0361 & 0.9783 & 0.9746 & 1.1613 & 0.8132 & 0.7093 \\
\hline 10. & $C_{l i}$ & $\mathbf{0 . 3 4 2 8}$ & 0.3460 & 0.3408 & 0.3426 & 0.3423 & 0.3415 & 0.3407 \\
\hline 11. & $\alpha_{i}\left(\alpha_{c}\right)$ & - & 1.8 & 2.4 & 2.1 & 0.8 & 2.5 & 2.8 \\
\hline
\end{tabular}

On the bases of obtained highest weighed value on design functional requirements for the wing airfoil section Eppler e186 (72.5\%), it is taken as basic airfoil section for further design process. For design back-up also the next airfoil sections with highest weighed values are taken and that is Wartman fx66h80 (6505\%). 
After evaluation of other parameters (stall angle $-\alpha_{s},\left(C_{l} / C_{d}\right)_{\max }$ ratio, etc.), that have influence on design requirement approaching, the decision is made to design wing from two airfoil sections: Eppler e186 and Wartman fx66h80. The airfoil section Wartman fx66h80 provides biggest $\left(C_{l} / C_{d}\right)_{\max }$ ratio, that in turn provides biggest endurance.

Evaluating airfoil section polar data parameters (Fig. 2), was noticed that for both airfoil sections longitudinal pitching moment $\left(C_{m}\right) 0$ (zero) value is on incidence angle difference of $1.5^{\circ}$ and for selected basic airfoil section (Eppler e186) it is smaller (Fig. 2). Referring to before mentioned decision is made to construct wing from two airfoil section in following way - inboard part: Wartman fx66h80, outboard part: Eppler e186, that should provide for the air vehicle favourable conditions during cruising and loitering flights with minimum energy consumption, good stability and in case of necessity will give time for air vehicle recovery [12-22; 26-28].

That also satisfies requirement that wing outboard part should get in stall condition later than inboard part near airframe.

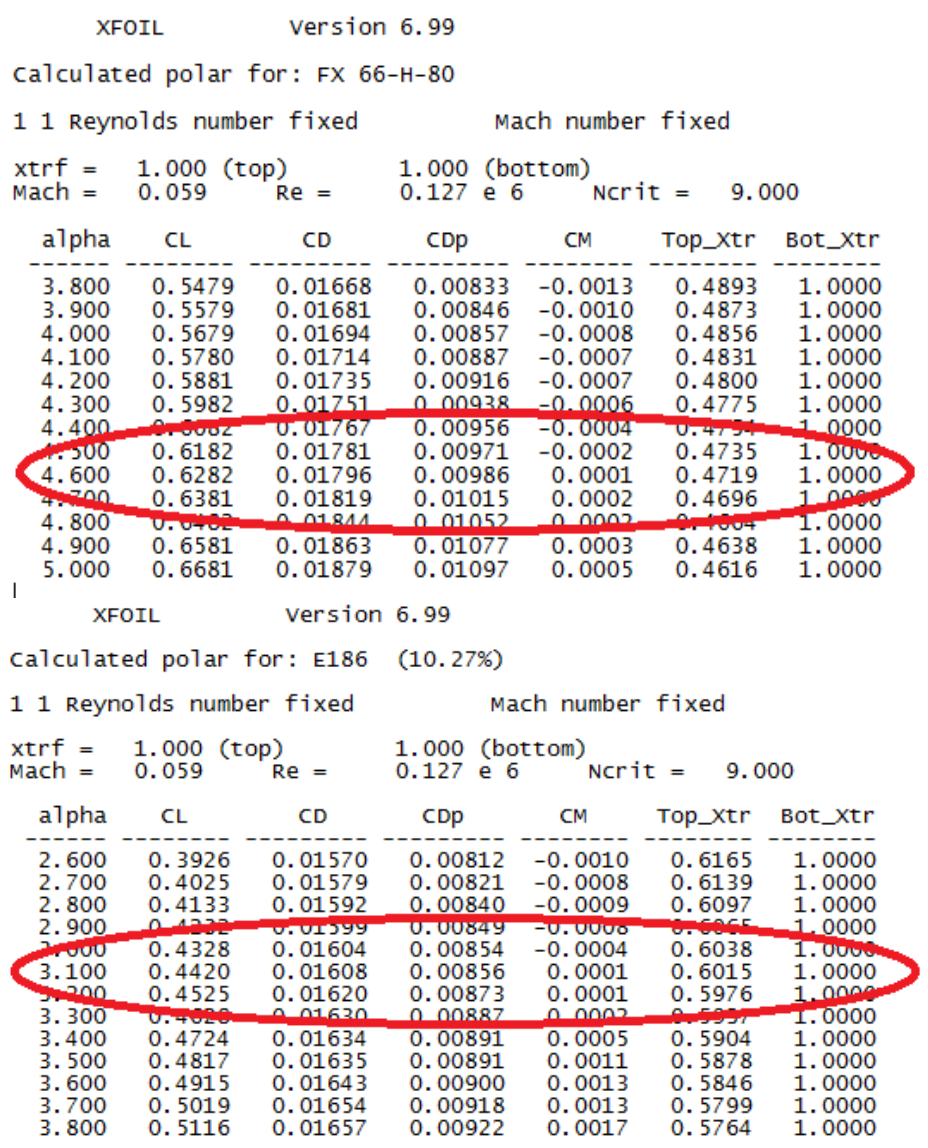

Fig. 2. The airfoil comparison chart

The wing airfoil setting angle $\left(\alpha_{\text {set }}\right)$

In following step is necessary to determine the wing airfoil section setting angle or incidence angle $\left(\alpha_{s e t}\right.$ or $\left.i_{w}\right)$ against airframe horizontal axe, that in accordance with previous data (Fig.2) are $4.6^{\circ}$ for inboard and $3.1^{\circ}$ for outboard section and is taken for initial design phase, but can be altered in further steps if necessary.

The wing incidence must satisfy the following design requirements:

1. The wing must generate the desired lift coefficient during cruising flight.

2. The wing must produce minimum drag during cruising flight.

3. The wing setting angle must ensure safe take-off operation, safely increase angle of attack.

4. The wing setting angle must ensure minimum fuselage drag during cruising flight (the fuselage angle of attack must be zero in cruise). 


\section{Conclusion}

The obtained results give good preliminary view on aircraft aerodynamic characteristics. As it was mentioned previously, airfoil selection was completed for flying wing air vehicle configuration that has inherent stability and control problems. The selection process in this research step provided information for complete wing design configuration for resolving stability problem. The selected airfoils should be integrated in $C A D$ software wing design model, tested in $C F D$ software and results compared with obtained in calculations. In further work the RPAS air vehicle wing planform parameters will be calculated, and, together with selected airfoils integrated in $C A D$ wing model. The wing $C A D$ model will be tested in $C F D$ software.

\section{Acknowledgements}

This work has been supported by the Latvian Council of Science (project "Design and modelling of Aerospace System for Launching pico- and nano- Satellites to Low Earth Orbit (LatLaunch)".
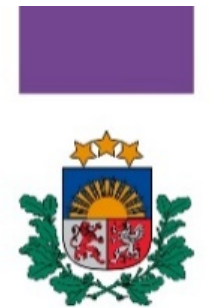

Latvian Council of Science

\section{References}

[1] U.S. Department of Transportation. Federal Aviation Administration. Advisory Circular: Aircraft Weight and Balance Control. Washington, D.C., 2005. [Online].

[2] Sadraey M. Aircraft Design. New Hampshire: John Wiley \& Sons, 2013. 800 p.

[3] Roskam J. Airplane Design. Vol. I. DAR Corporation, 2005.

[4] Austin R. Unmanned Aircraft Systems: UAVS Design, Development and Deployment. First Edition. New Jersey: John Wiley \& Sons, 2010. 332 p.

[5] Valavani K. P. Advances in Unmanned Aerial Vehicles. Springer, 2007. 543 p.

[6] Glizde N. Urbaha M. Remotely piloted aircraft system air vehicle type selection. Paper presented at the Engineering for Rural Development, 2019. 18, pp. 1302-1312.

[7] Gorelikovs D., Urbaha M. Control of agricultural land flooding by using remotely piloted aircraft system. Paper presented at the Engineering for Rural Development, 2019. 18, pp. 1655-1660.

[8] Gorelikovs D., Urbaha M., Urbahs A., Stankunas J. Automatic routing for the flyby of monitoring objects by a remotely piloted aircraft. Paper presented at the Procedia Computer Science, 2019. 149 , pp. 398-405.

[9] Urbahs A., Petuhova J., Urbaha M., Carjova K., Andrejeva D. Monitoring of forest (fire) using micro class unmanned aerial vehicles, 2013, pp. 61-65.

[10] Roskam J. Lessons Learned in Aircraft Design. DAR Corporation, 2007.

[11] Roskam J. Airplane Design. Washington, D. C.: American Institute of Aeronautics and Astronautics, 2003. $760 \mathrm{p}$.

[12] Bertin L. J., Cummings R. M. Aerodynamics for Engineers. Fifth edition. Pearson: Prentice Hall, 2009. $614 \mathrm{p}$.

[13] Blanchard B. S., Fabrycky W. J. Systems Engineering and Analysis. Fourth edition. Prentice Hall, 2006. $726 \mathrm{p}$.

[14]Lan E. C. T., Roskam J. Airplane Aerodynamics and Performance. Lawrence: DAR Corporation, 2003. $743 \mathrm{p}$.

[15] Sadraey M. Aircraft Performance Analysis. Boka Raton: Taylor \& Francis Group, 2017. 572 p.

[16] Lan E. C. T., Roskam J. Airplane Performance and Design. Torrance: Crawford Aviation, 2003. $250 \mathrm{p}$.

[17] Bertin L. J., Cummings R.M. Aerodynamics for Engineers, Fifth edition, Pearson: Prentice Hall, 2009. $465 \mathrm{p}$. 
[18] McCormick B.W. Aerodynamics, Aeronautics and Flight Mechanics. Wiley-VCH Verlag GmbH, 1979. $367 \mathrm{p}$.

[19] Torenbeek E. Synthesis of Subsonic Airplane Design. Delft University Press, 1996. 270 p.

[20] Stinton D. The Design of the Aeroplane. AIAA, 2001. 395 p.

[21] Hepperle M. http://www.MH-AeroTools.de/, 2006.

[22] Randal W., Timothy W., Small Unmanned Aircraft: Theory and Practice. The United Kingdom: Princeton University Press, 2012. 317 p.

[23]Blanchard B.S., Fabrycky W.J. Systems Engineering and Analysis. Fourth edition. Pearson: Prentice Hall, 2006. 365 p.

[24] Kroo I., Altus S., Braun R., Gage P., Sobieski I. Multidisciplinary Optimization Methods for Aircraft Preliminary Design. 5th Symposium on Multidisciplinary Analysis and Optimization, Sep. 1994.

[25] Kroo I., Altus S., Braun R. Multidisciplinary Optimization Methods for Aircraft Preliminary Design. AIAA 94-4325, 1994.

[26] David G. Fundamentals of Airplane Flight Mechanics. Fourth edition. Heidelberg: SpringerVerlag, 2007. $405 \mathrm{p}$.

[27] Urbahs A., Urbaha M., Carjova K., Koruba Z. Technological solutions for the computer-aided design and manufacturing of a remotely piloted aircraft. Paper presented at the Procedia Computer Science, 2019. 149, pp. 390-397.

[28] Urbahs A., Urbaha M., Petrovs V., Jakovlevs A. Methods and means of the computer-aided design of unmanned aerial vehicle model. Paper presented at the Proceedings - 2009 International Conference on Intelligent Engineering Systems, INES 2009, pp. 211-213. 